This item was submitted to Loughborough's Research Repository by the author.

Items in Figshare are protected by copyright, with all rights reserved, unless otherwise indicated.

\title{
Real-world performance of catalytic converters
}

PLEASE CITE THE PUBLISHED VERSION

PUBLISHER

Professional Engineering Publishing / @ IMECHE

VERSION

VoR (Version of Record)

LICENCE

CC BY-NC-ND 4.0

REPOSITORY RECORD

Samuel, S., D. Morrey, Mark Fowkes, D.H.C. Taylor, Colin P. Garner, and L. Austin. 2019. "Real-world Performance of Catalytic Converters". figshare. https://hdl.handle.net/2134/4835. 
This item was submitted to Loughborough's Institutional Repository (https://dspace.lboro.ac.uk/) by the author and is made available under the following Creative Commons Licence conditions.

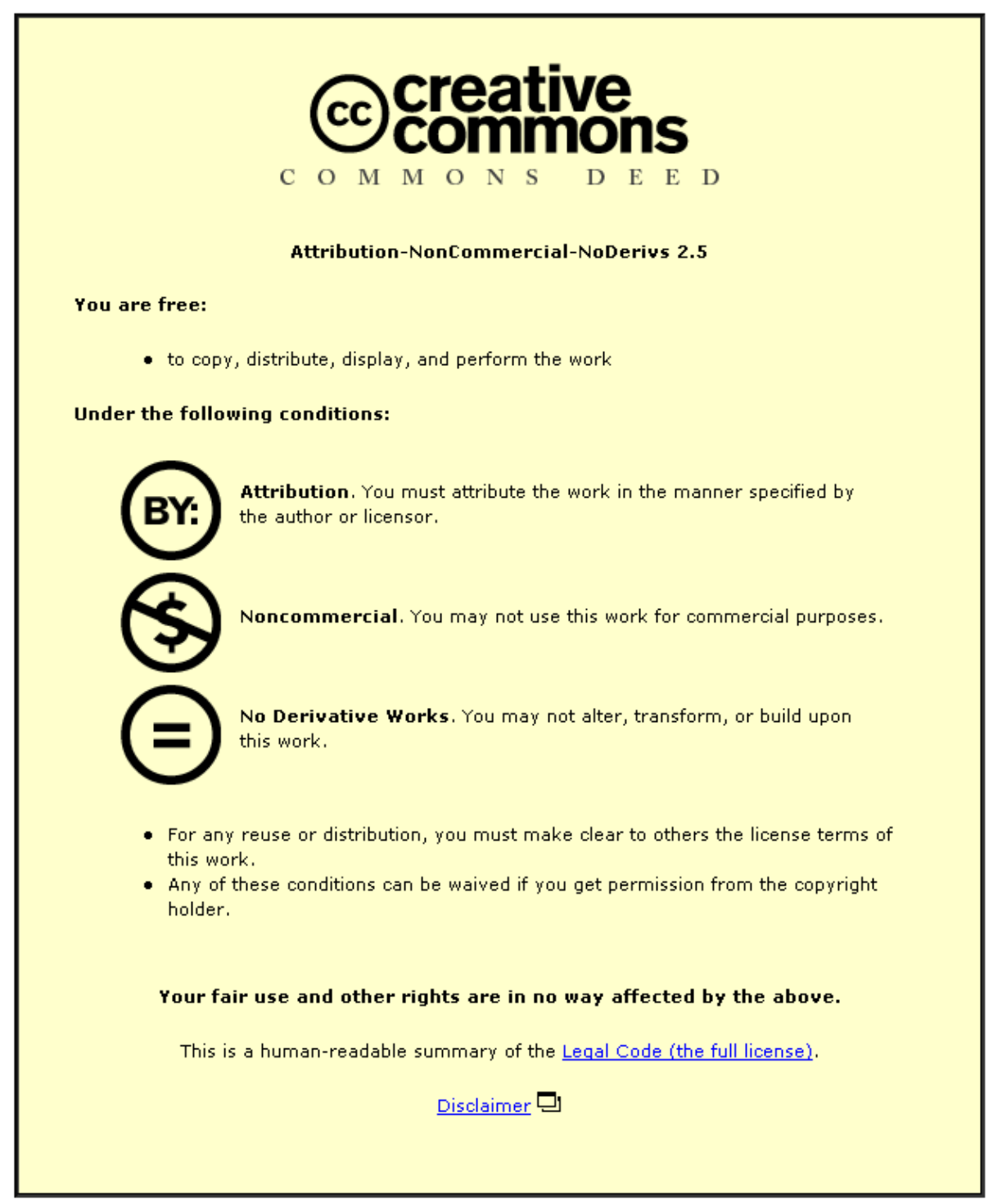

For the full text of this licence, please go to: http://creativecommons.org/licenses/by-nc-nd/2.5/ 


\title{
Real-world performance of catalytic converters
}

\author{
S Samuel $^{\text {* }}$, D Morrey ${ }^{1}$, M Fowkes ${ }^{2}$, D H C Taylor ${ }^{3}$, C P Garner ${ }^{3}$, and L Austin ${ }^{4}$ \\ ${ }^{1}$ Oxford Brookes University, Oxford, UK \\ ${ }^{2}$ MIRA, UK \\ ${ }^{3}$ Loughborough University, Loughborough, UK \\ ${ }^{4}$ University of Surrey, Guildford, UK
}

The manuscript was received on 26 March 2004 and was accepted after revision for publication on 13 January 2005.

DOI: $10.1243 / 095440705 X 28349$

\begin{abstract}
This paper investigates experimentally the performance of a three-way catalytic (TWC) converter for real-world passenger car driving in the United Kingdom. A systematic approach is followed for the analysis using a Euro-IV vehicle coupled with a TWC converter. The analysis shows that the real-world performance of TWC converters is significantly different from the performance established on legislative test cycles. It is identified that a light-duty passenger vehicle certified for Euro-IV emissions reaches the gross polluting threshold limits during real-world driving conditions. This result is shown to have implications for overall emission levels and the use of remote emissions sensing and on-board diagnostics (OBD) systems.
\end{abstract}

Keywords: vehicle, catalytic converters, real-world, performance, emissions, drive-cycle

\section{INTRODUCTION}

Although substantial progress has been made in reducing legislative drive-cycle vehicle emission levels by the employment of three-way catalytic (TWC) converters, there has been significantly less improvement in actual real-world driving emission levels. The determining factors for the levels of the realworld emissions can be grouped into two main categories. The first category consists of engine-out (i.e. pre-catalyst) emissions levels for steady-state and transient engine operating conditions. The second category consists of the conversion efficiency of the catalytic converter during both steady-state and transient engine operation.

Published literature for the second category shows that the numerical simulation models can simulate well the steady-state and transient performance of catalytic converters for given legislative drive-cycles [1-5]. However, due to fundamental limitations in the understanding of in-cylinder carbon monoxide (CO) formation, as well as the mechanism of $\mathrm{CO}$ oxidation over catalyst surfaces [6, 7], simulation studies have not to date been extended successfully

* Corresponding author: School of Technology, Oxford Brookes University, Gipsy Lane Campus, Headington, Oxford OX3 OBP, UK.email: s.samuel@brookes.ac.uk to the real-world transient performance of the TWC. In addition, the purpose of the employment of the catalytic converter has in reality been mainly to fulfil the legislative requirements rather than realworld emission performance. The behaviour of the catalytic converter under transient conditions has been studied by various researchers [3-5] motivated by the need for a reliable catalytic converter model to support the design of demanding exhaust after treatment systems. However, the understanding and control of the performance of actual catalytic converters for real-world driving is essential if the real-world emission levels are to be improved. Hence, this present study has investigated the real-world performance of a catalytic converter using an experimental vehicle that was certified for Euro-IV legislative limits and used a TWC converter.

\section{EXPERIMENTS}

The present work used a Euro-IV, 1.4 litre, fourstroke, gasoline multi-point port injection, light-duty passenger vehicle of mass $945 \mathrm{~kg}$. This vehicle was tested at the Motor Industries Research Association (MIRA) [8] on a chassis dynamometer using two drive-cycles, namely the legislative ECE + EUDC drive-cycle (see Fig. 1), and what the present authors 


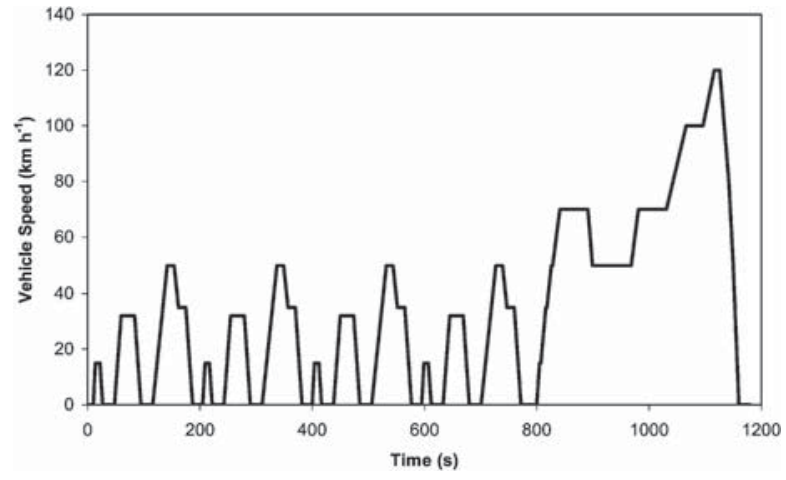

Fig. 1 ECE + EUDC drive-cycle used for the experiments

term 'the Harsh-MIRA drive-cycle' (shown in Fig. 2). The latter drive cycle seeks to represent the harshest driving considered possible with this type of vehicle in the United Kingdom.

This research was a part of a project called AVERT [9], supported by the Department of Trade and Industry (DTI) Foresight Vehicle initiative in the United Kingdom. The analysis was divided into two sections. The first section focused on the design performance of the catalytic converter used on an experimental engine, and the second section of the analysis focused on the real-world performance of the catalytic converter, and particularly CO emissions, since these are known to have very high levels under real-world driving conditions [10].

\section{DESIGN PERFORMANCE OF A CATALYTIC CONVERTER}

The purpose of a TWC converter is to convert CO, hydrocarbon $(\mathrm{HC})$, and oxides of nitrogen $\left(\mathrm{NO}_{x}\right)$ emissions from an engine into carbon dioxide $\left(\mathrm{CO}_{2}\right)$ and water $\left(\mathrm{H}_{2} \mathrm{O}\right)$, so that tail-pipe emissions are at acceptable levels. Once the catalyst has reached its operating temperature, the optimal conversion efficiency for all three emission components lies within a

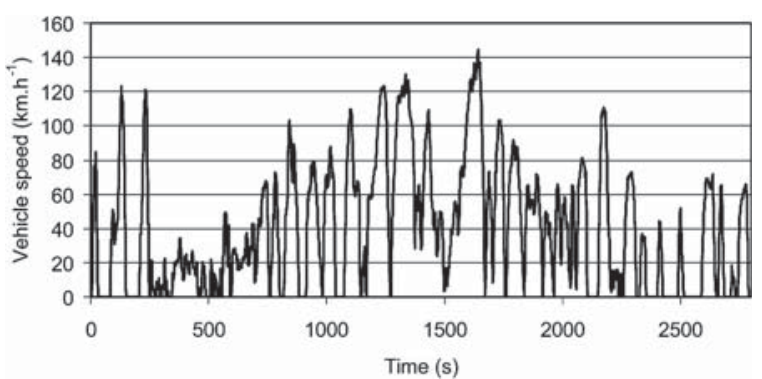

Fig. 2 The Harsh-MIRA drive-cycle that represents the harshest possible driving in the United Kingdom using the particular experimental vehicle narrow band of air-fuel ratio near the stoichiometric $(\lambda=1)$, as illustrated in Fig. 3. Although the specific details vary with catalyst formulation, the narrow window is a common feature of all standard TWC converter systems [2]. The pre- and post-catalyst CO levels for the legislative ECE + EUDC drive-cycle are given in Fig. 4. It can be seen that the higher levels of tailpipe $\mathrm{CO}$ occur only during the start of the cycle for a duration of about $10 \mathrm{~s}$. The pre- and postcatalyst $\mathrm{CO}$ values for the high-speed segment of the ECE + EUDC drive-cycle are shown in Fig. 5. The $\lambda$-values estimated using the Spindt method [11] from the pre-catalyst emission values of drive-cycle test results are shown in Fig. 6 . The Spindt method has been used widely and is known to give air-fuel ratio measurements based on engine-out emissions species with an accuracy of \pm 2 per cent [11].

Figure 7 shows the conversion efficiency of the catalytic converter for the legislative drive-cycle as a function of percentile of vehicle operating points. This shows that only in up to 3rd percentile of the vehicle operating points does the catalytic converter efficiency fall below 90 per cent and only up to 5th percentile of the vehicle operating points have CO conversion efficiency less than 97 per cent. In general, the remainder of the vehicle operating points have $\mathrm{CO}$ conversion efficiencies of 99.9 per cent for the legislative drive-cycle.

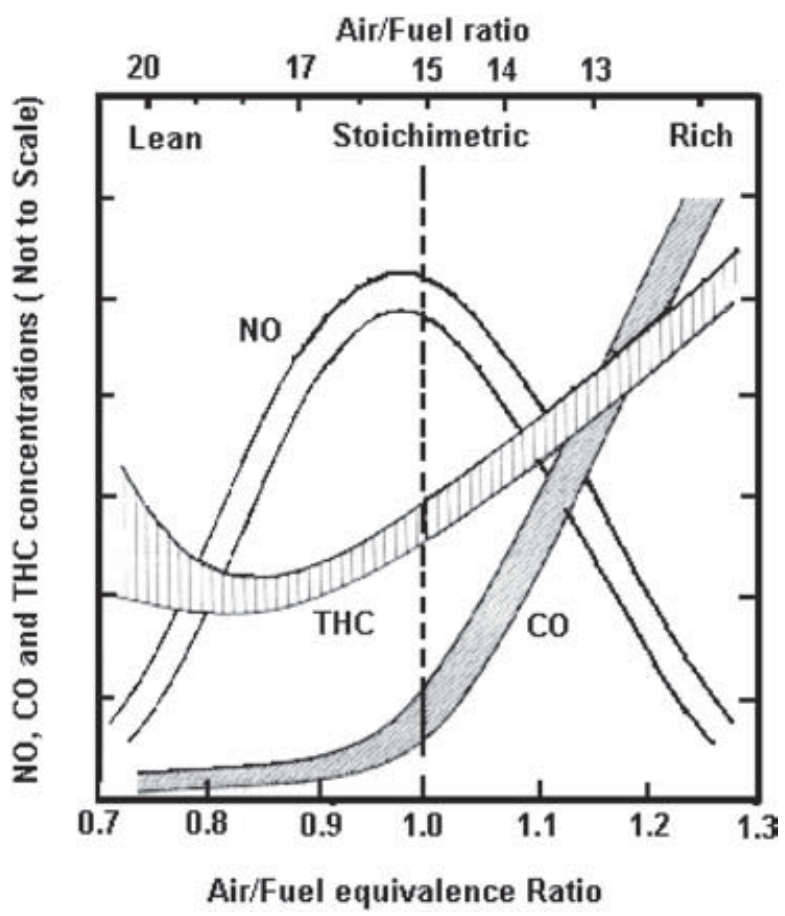

Fig. 3 Schematic diagram illustrating the effect of airfuel ratio on engine-out (pre-catalyst) emission levels [2] 

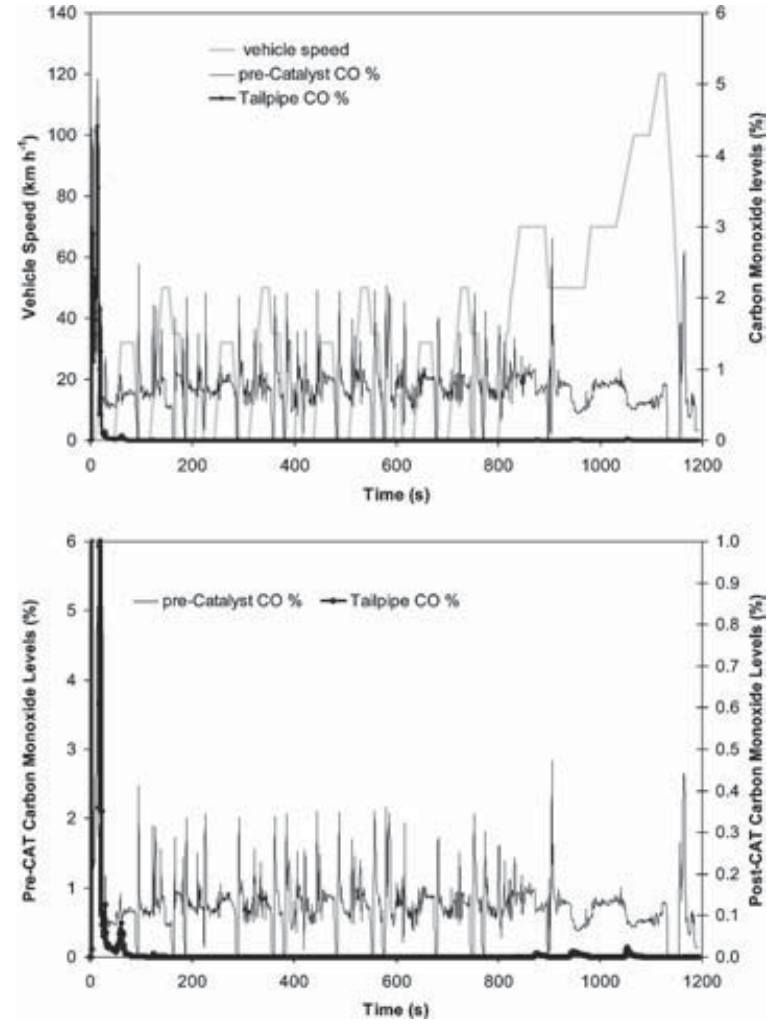

Fig. 4 Pre- and post-catalyst CO per cent for ECE + EUDC drive-cycle

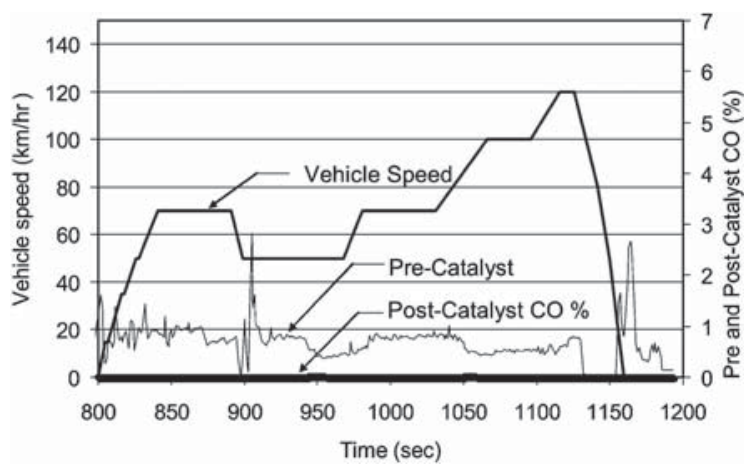

Fig. 5 Pre- and post-catalyst CO per cent for EUDC (high-speed segment) drive-cycle

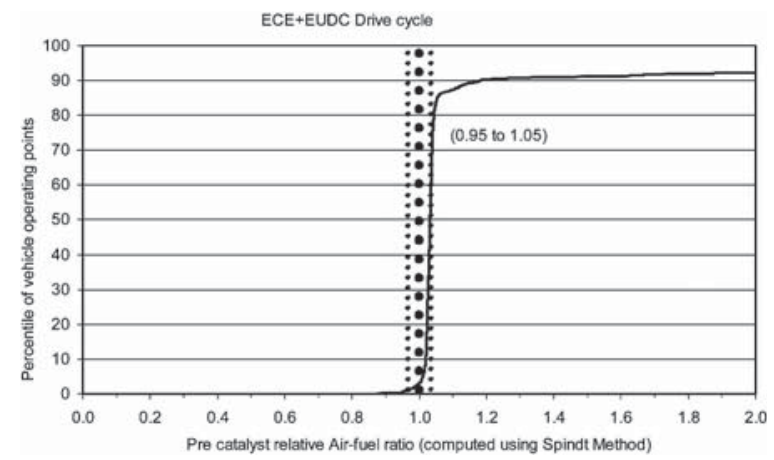

Fig. 6 Relative air-fuel ratio value for the legislative drive-cycle

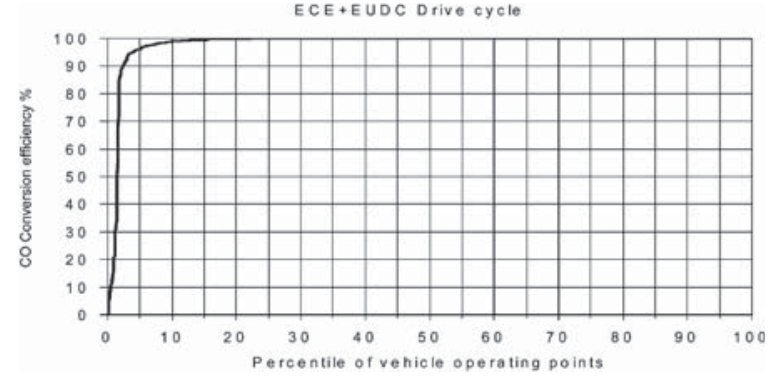

Fig. 7 CO conversion efficiency of the catalytic converter for ECE + EUDC drive-cycle

The higher conversion efficiency of the catalytic converter for the legislative drive-cycle can be explained as follows. Oxygen-deficient combustion of HC fuels generates $\mathrm{CO}$ (CO can be generated even in conditions of plentiful oxygen through the dissociation of $\mathrm{CO}_{2}$, at some specific pressures and temperatures) and thus, the air-fuel ratio effectively dictates the CO formation. Simply, if there is insufficient oxygen available to burn all the fuel, then the partial reaction products are created. Since the $\mathrm{CO}$ molecule is on the main reaction path in HC combustion, if there are insufficient oxygen molecules available for that combustion, then some CO molecules are produced. Unburned HC molecules, for similar reasons, usually accompany these CO molecules. Since the engine management system of the experimental vehicle controls the $\lambda$ value to $\geqslant 1$ for the entire legislative drive-cycle, the $\mathrm{CO}$ conversion efficiency of the catalytic converter is greater than 90 per cent. In addition, the pre-catalyst CO values are low, since $\lambda$ is greater than 1 . However, the real-world performance of the catalytic converter is found to be significantly different from its performance on the legislative drive-cycle, since the precatalyst CO loading is significantly different from that exhibited in the legislative drive-cycle.

\section{REAL-WORLD PERFORMANCE OF THE CATALYTIC CONVERTER}

Experiments were carried out using the 'Harsh-MIRA' drive-cycle described earlier. The Harsh-MIRA drivecycle was defined as the harshest driving style considered possible with the present experimental vehicle in a typical road network in the United Kingdom. The pre-catalyst emissions were recorded every second. Similarly, the post-catalyst emissions were recorded using both constant volume sampler (CVS) bag and second-by-second trace methods. These experiments were repeated three times to ensure experimental consistency and repeatability. 
The $\lambda$ value was estimated using the exhaust gas composition. The $\lambda$ value against the percentile of vehicle operating points is shown in Fig. 8 for the Harsh-MIRA drive-cycle. The difference between the closed-looped $\lambda$ control for the legislative drive-cycle (see Fig. 6) and the real-world drive-cycle (see Fig. 8) was compared. The $\lambda$ value for the legislative drivecycle was always found to be greater than 1 . The CO conversion efficiency of the TWC converter was close to 100 per cent for $\lambda$ values greater than 1 , as can be seen in Figs 6 and 7. Hence, the CO conversion efficiency was greater than 99.9 per cent for the ECE + EUDC drive-cycle except during the early stages of the cycle. One of the probable reasons for low conversion efficiency during the early stages of the cycle may be the low operating temperature of the catalytic converter. Although the vehicle and engine were tested under fully pre-warmed conditions, the catalyst might not have reached its full operating temperature during the start of the drivecycle.

The $\lambda$ value against percentile of vehicle operating points for the Harsh-MIRA drive-cycle is shown in Fig. 8. It is evident that up to the 20th percentile of the vehicle operating points are inside the rich-fuel mode or outside the $\lambda$ control zone of the engine and up to the 70th percentile of the vehicle operating points have $\lambda$ values less than 1 .

The pre- and post-catalyst CO values for the HarshMIRA drive cycle are shown in Figs 9 and 10. It can be seen that post-catalyst CO levels were high and close to the pre-catalyst values for parts of the drivecycle. For example, the CO conversion efficiency drops to low values during the 1550-1700 s interval of the drive-cycle. The percentile of vehicle operating points against $\mathrm{CO}$ conversion efficiency is given in Fig. 11. Notably, up to 24th percentile of the vehicle operating points operate below 90 per cent of conversion efficiency and up to 10th percentile of the

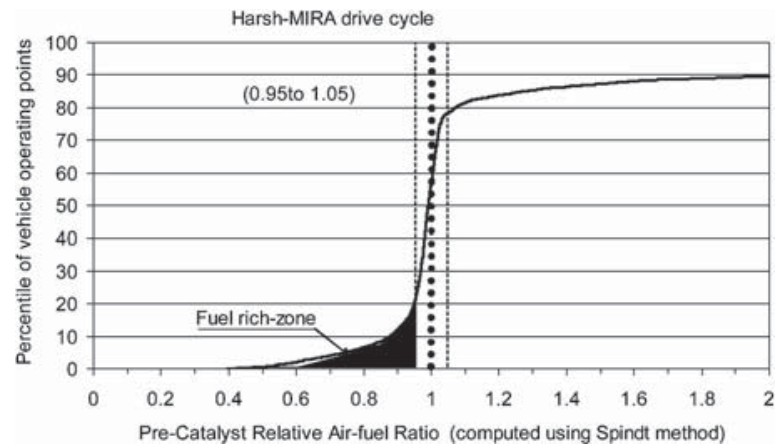

Fig. 8 Relative air-fuel ratio $\lambda$ value of the experimental vehicle while driving using the HarshMIRA drive-cycle
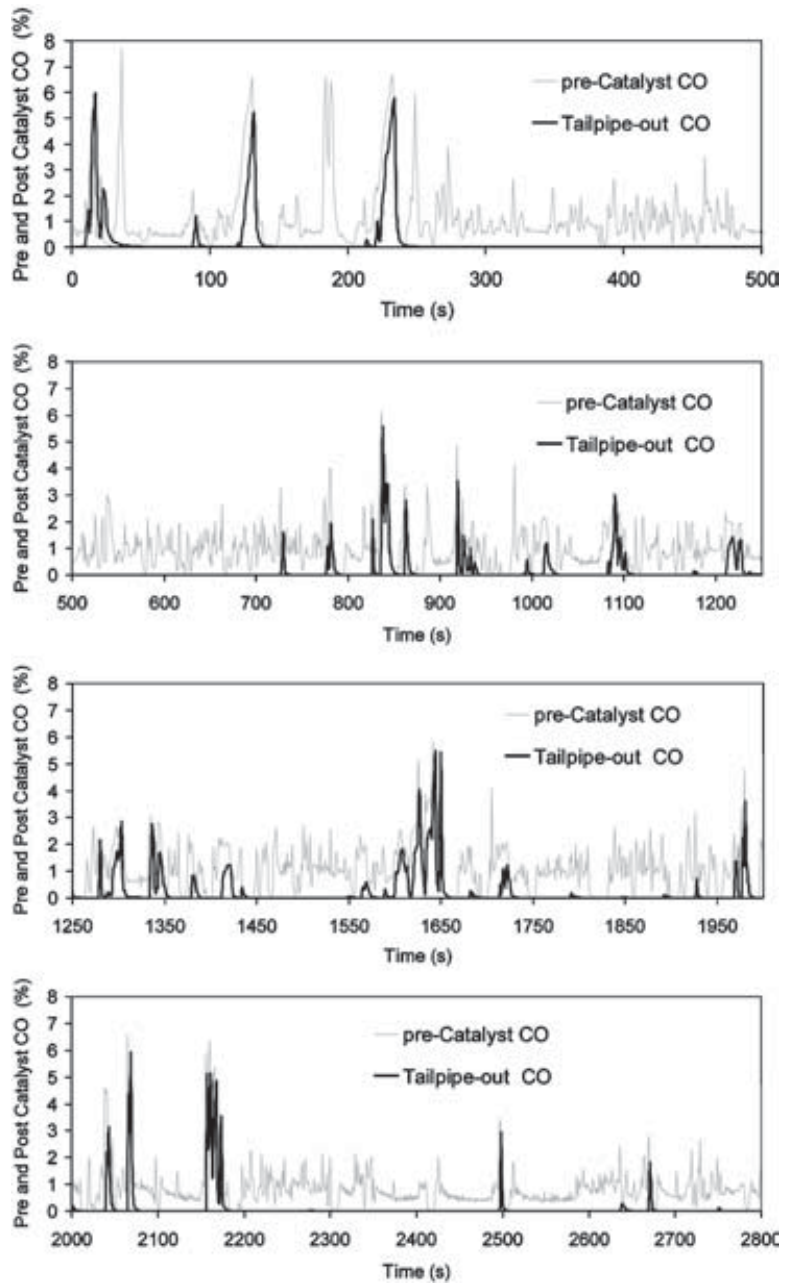

Fig. 9 Pre- and post-catalyst CO per cent for the HarshMIRA drive-cycle

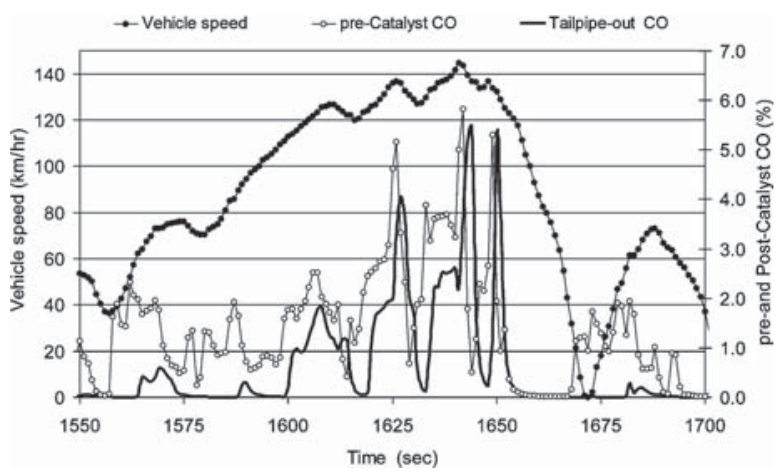

Fig. 10 Pre- and post-catalyst CO per cent for the highspeed segment of the Harsh-MIRA drive-cycle

vehicle operating points operate below 60 per cent of the CO conversion efficiency; and up to 3rd percentile of the vehicle operating points operate with 0 per cent conversion efficiency. Hence, the actual conversion efficiency of the catalytic converter for the real-world drive-cycle is significantly worse than that for the legislative drive-cycle. The overall CO 


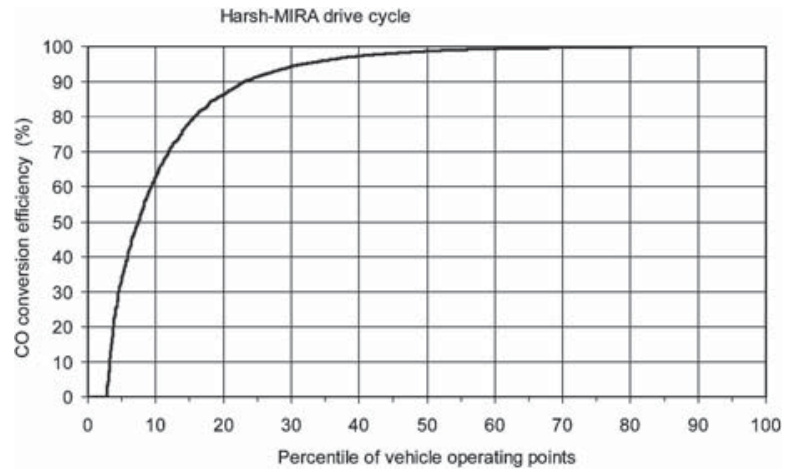

Fig. 11 Real-world conversion efficiency of the catalytic converter of the experimental vehicle for the Harsh-MIRA drive-cycle

conversion efficiency of the converter for all three tests is given in Table 1 and ranged from 72 to 75 per cent. This is significantly lower than the conversion efficiency of the catalytic converter for ECE + EUDC drive-cycle, which is greater than 99 per cent. The tailpipe-out CO levels for the ECE + EUDC drive cycle and the Harsh-MIRA drive cycle against the vehicle speed and acceleration is shown in Fig. 12. It is evident from Fig. 12 that the real-world performance of the catalytic converter is significantly different from the performance established on legislative test-cycles.

Another noticeable behaviour of the catalytic converter is the oscillation of tailpipe $\mathrm{CO}$ shown in Fig. 10. This result has significant implications if systems are to be adopted that remotely sense on-road vehicle $\mathrm{CO}$ and $\mathrm{HC}$ emissions. For example, Stedman et al. [12] in California faced repeatability challenges while carrying out real-world, on-road emission measurement using remote sensing. When their experiments were repeated using remote sensing for the same vehicle, the greatest variation (factors of 10 to 20 in exhaust concentration of $\mathrm{CO}$ ) occurred under hard acceleration conditions. In addition, there were several circumstances in which a vehicle that would routinely pass a Federal Test Procedure (FTP) test might in practice be measured as an on-road polluter. In contrast, Stedman et al. $[12,13]$ also identified that low-emitting vehicles exhibit little test-to-test variability. The results of

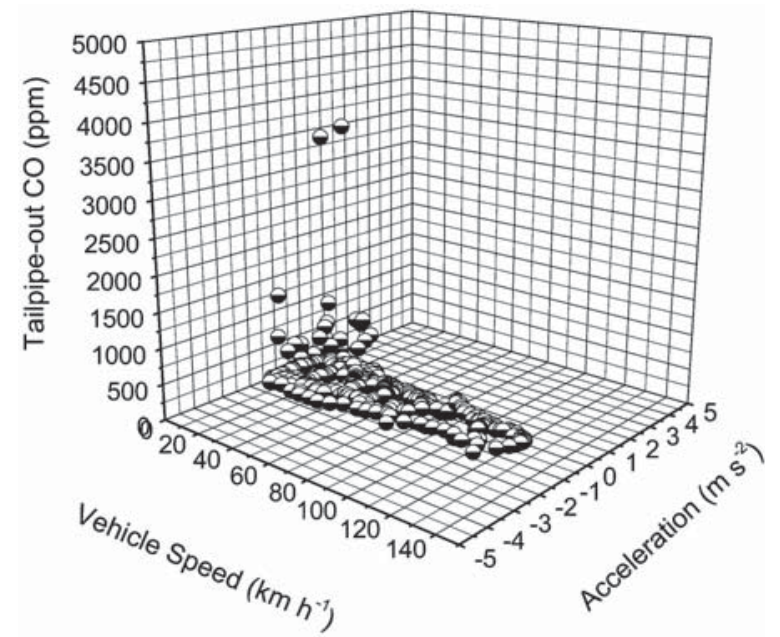

(a) For the ECE legislative drive cycle

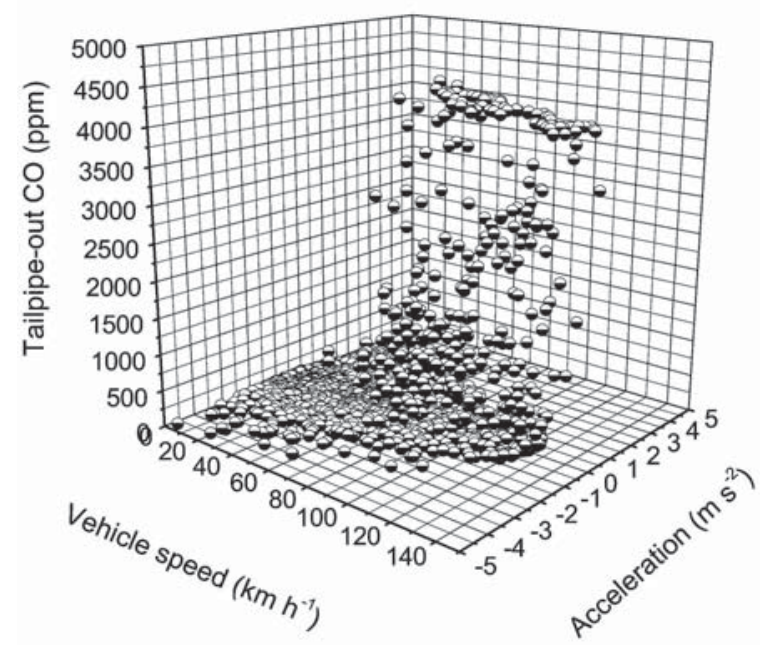

(b) For the harsh-MIRA drive cycle

Fig. 12 Tailpipe-out CO levels for the ECE legislative drive-cycle and the Harsh-MIRA drive-cycle

Stedman et al. $[\mathbf{1 2}, \mathbf{1 3}]$ can be compared with the experimental results of the Harsh-MIRA drive-cycles obtained here. The oscillations became predominant for the Harsh-MIRA drive-cycle since the vehicle operating points remained outside the lean operating region (and hence clean zone of the engine operating map) of the engine, as shown in Fig. 8. If remote sensing techniques are used to measure the tailpipe

Table 1 Real-world efficiency of the catalytic converter

\begin{tabular}{lllll}
\hline Test number & $\begin{array}{l}\text { Total distance } \\
(\mathrm{km})\end{array}$ & $\begin{array}{l}\text { Total CO emission } \\
\text { pre-catalyst from } \\
\text { the experiment }(\mathrm{g})\end{array}$ & $\begin{array}{l}\text { Total CO emission } \\
\text { post catalyst }(\mathrm{g})\end{array}$ & $\begin{array}{l}\text { Overall CO conversion } \\
\text { efficiency of the } \\
\text { catalyst }(\%)\end{array}$ \\
\hline Test 1 & 31.11 & 540 & 141 & 74 \\
Test 2 & 31.05 & 565 & 156 & 72 \\
Test 3 & 31.09 & 522 & 131 & 75 \\
\hline
\end{tabular}


CO during the Harsh-MIRA drive-cycle, the repeatability would be poor, since the tailpipe $\mathrm{CO}$ fluctuates from $4200 \mathrm{ppm}$ to low levels of up to $100 \mathrm{ppm}$. The United States General Accounting Office also documented similar tailpipe emission levels [14], with a list of 18 vehicles that failed an initial inspection and maintenance test (I/M240) but passed a second test without any alterations or repairs being made to the vehicle.

Remote sensing has been criticized elsewhere in the United States for displaying highly variable emission levels $[\mathbf{1 2}, \mathbf{1 5}]$ on repeated remote sensing measurements. If the vehicles are allowed to operate inside the high-emission zone of the engine performance map, the remote sensing method becomes almost meaningless, due to the high variability between the tests. On-board diagnostics (OBD) measurements can be used as an alternative to remote sensing. However, the practical application of OBD has been shown to face similar real-world challenges with regard to repeatability. For example, when Sierra [16] conducted experiments using the OBD system for the application of real-world driving conditions, fault codes were set at 1.5 times the threshold limits. This OBD system repeatedly registered fault codes indicating malfunction of the exhaust gas after-treatment system. However, no evidence was found to indicate an actual malfunction of the exhaust gas after-treatment system when it was examined. Hence, it was concluded that the emission levels during real-world driving conditions were oscillating and at times were higher than the set threshold limits $[\mathbf{1 7}, \mathbf{1 8}]$. The present analysis adds to these findings in that, if the vehicles are being driven aggressively, and also if the vehicle operating points remain outside the clean zone of the engine map, the engine emission levels will be high and variable and will trigger the malfunction indicator to register fault codes in the OBD. Hence, the appli- cation of OBD becomes inconclusive for the vehicle if it is driven using a style such as the Harsh-MIRA drive-cycle. According to Austin et al. [19] many vehicles enter a power enrichment mode under heavy acceleration. Even though the work of Stedman et al. [13] identified large variabilities in tailpipe CO using remote sensing in Chicago, Stedman ruled out the possibility of the power enrichment effect for higher levels of $\mathrm{CO}$ and its fluctuations.

The work of Baum et al. [20] also displayed similar results with regard to repeatability, using remote sensing. Moreover, they also identified that dynamometer testing underestimates the tailpipe emissions, compared with remote sensing. However, the source for the higher variability has not been identified or reported in the literature, prior to the work presented in this paper.

\section{REAL-WORLD EMISSION LEVELS AND GROSS POLLUTING VEHICLES}

The present investigation has shown that realworld emission levels of a Euro-IV certified vehicle for a Harsh-MIRA drive-cycle are significantly greater than even Euro-I (i.e. 1990) certified vehicles. The instantaneous emission values are compared with the gross polluting threshold limits of Europe as given in Table 2. The threshold to define any vehicle as a gross polluter in Europe is also given in Table 2. The emission values of the Harsh-MIRA drive-cycle are compared with the threshold values. It is evident that tailpipe CO exceeded the threshold limits as shown in Fig. 13. Similarly, tailpipe total hydrocarbon (THC) is close to the threshold, but tailpipe $\mathrm{NO}_{x}$ has a 100 per cent threshold margin (see Figs 14 and 15).

Table 3 lists the order of priority for the gross polluter test by the legislators [21]. It is interesting to note that the highest priority has been given to

Table 2 Gross polluting vehicle limits $[\mathbf{2 1}, \mathbf{2 2}]$

\begin{tabular}{llll}
\hline Specie & $\begin{array}{l}\text { Legislative limits corresponding } \\
\text { to Euro 3-year 2000 }\end{array}$ & $\begin{array}{l}\text { Gross polluter } \\
\text { threshold value }\end{array}$ & Harsh-MIRA drive-cycle tailpipe peaks \\
\hline $\mathrm{CO}$ & $2.3 \mathrm{~g} / \mathrm{km}(\sim 0.3 \%)$ & $3-5 \%$ & $\begin{array}{l}1.5 \text { percentile of the data is above } 3 \% \mathrm{CO} \text { and the maximum is } 6 \% \mathrm{CO} \\
\mathrm{NO}\end{array}$ \\
$\mathrm{THC}$ & $0.15 \mathrm{~g} / \mathrm{km}(\sim 150 \mathrm{ppm})$ & $\begin{array}{l}2000-3000 \mathrm{ppm} \\
1500-2000 \mathrm{ppm}\end{array}$ & $\begin{array}{l}\text { Very much lower than the threshold } \\
0.5 \text { percentile of the data is above the threshold values }\end{array}$ \\
\hline
\end{tabular}

Table 3 Order of priority for specie detection by road inspectorates in order to designate the gross polluting vehicles [21]

\begin{tabular}{lll}
\hline Priority & Specie & Remarks from Harsh-MIRA drive-cycle results \\
\hline 1 (highest) & $\mathrm{NO}_{x}$ (or NO if total $\mathrm{NO}_{x}$ cannot be measured) & Safe; $100 \%$ margin available \\
2 & $\mathrm{CO}$ & No margin available from threshold values \\
3 & $\mathrm{HC}$ & At the threshold \\
\hline
\end{tabular}



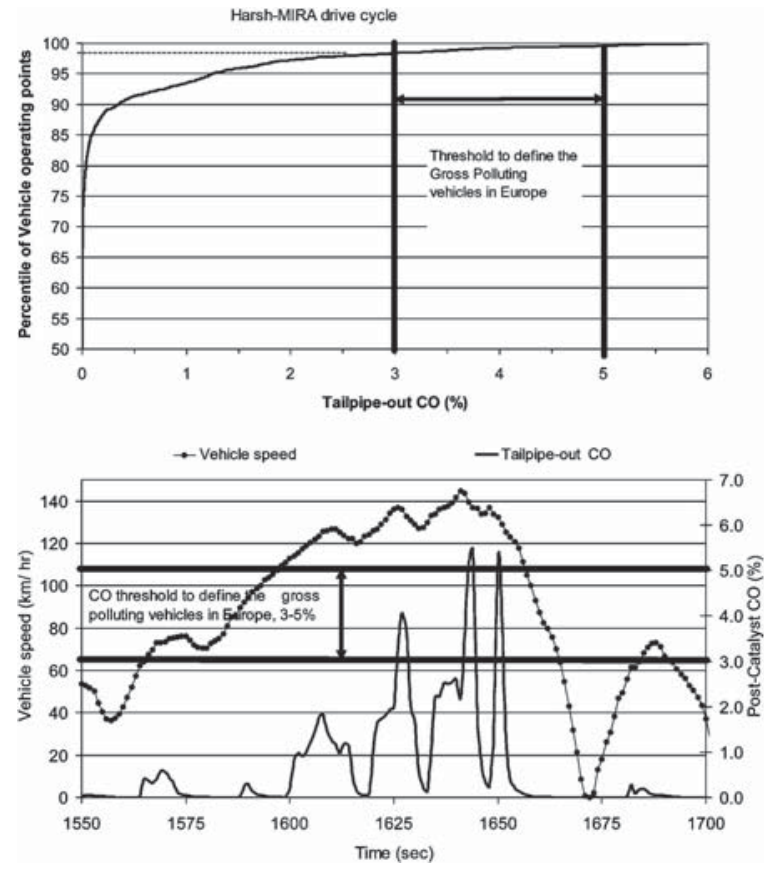

Fig. 13 Comparison of real-world tailpipe CO and the gross polluting CO levels specified in the legislation
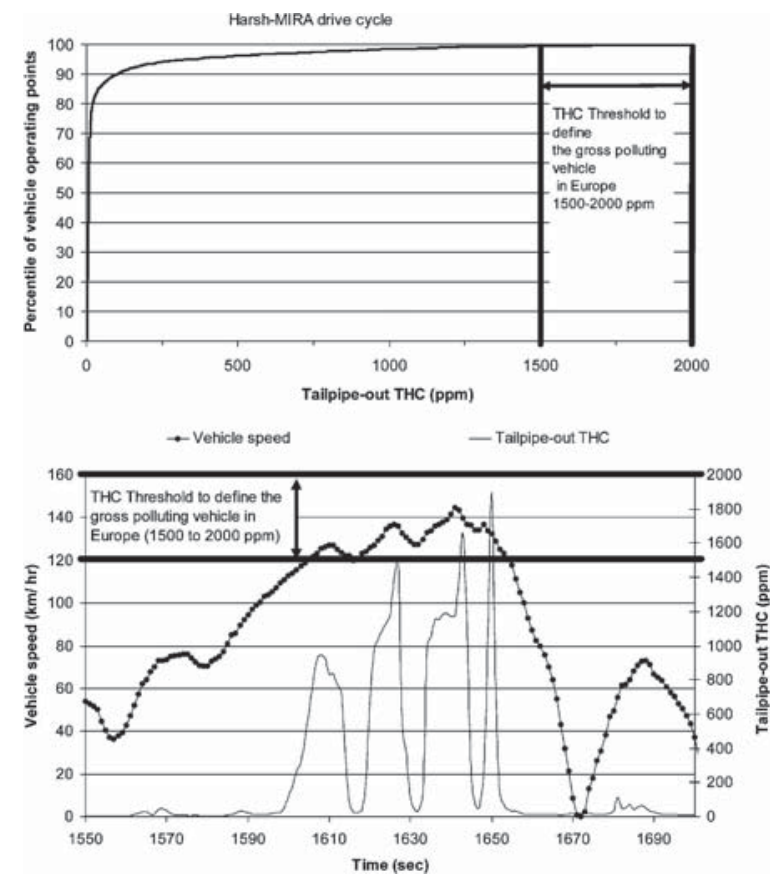

Fig. 14 Comparison of real-world tailpipe THC and the gross polluting THC levels specified in the legislation

tailpipe $\mathrm{NO}_{x}$ and the experimental vehicle used had the highest safety margin for tailpipe $\mathrm{NO}_{x}$, even for the Harsh-MIRA drive-cycle. However, tailpipe CO is the most severely worsened emission specie under real-world driving conditions.
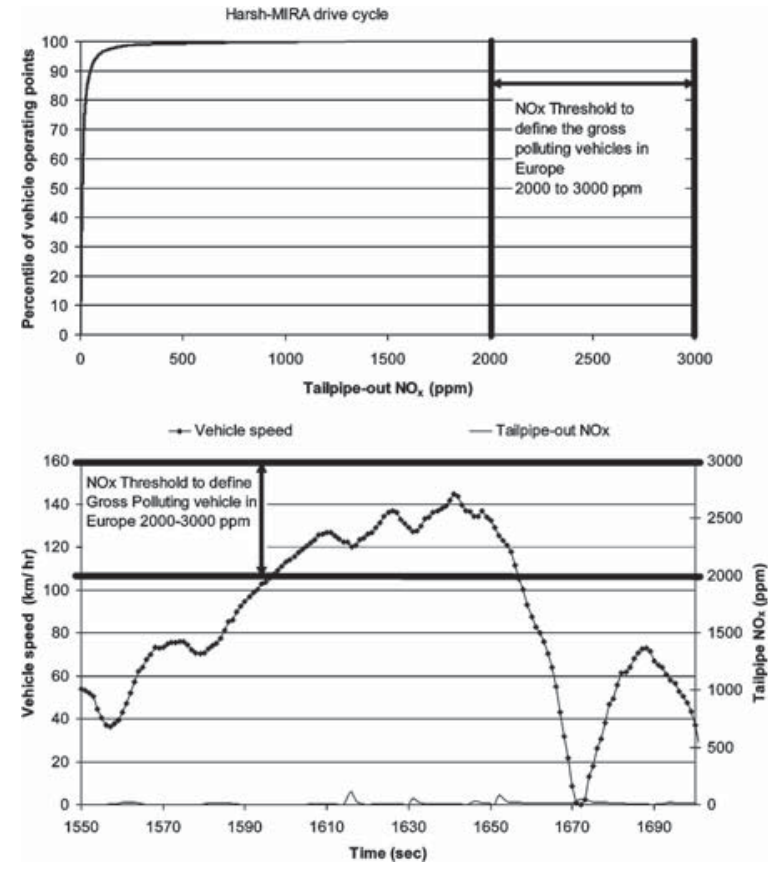

Fig. 15 Comparison of real-world tailpipe $\mathrm{NO}_{x}$ and the gross polluting $\mathrm{NO}_{x}$ levels specified in the legislation

\section{CONCLUSIONS}

The pre- and post-catalyst emission measurements showed that up to 3rd percentile of vehicle operating points have catalytic converter efficiencies close to zero for the Harsh-MIRA drive-cycle. Hence, the vehicle emissions during that period are virtually the same as a non-catalyst-equipped vehicle. In addition, the tailpipe $\mathrm{CO}$ produced during catalytic converter low-efficiency periods is high compared to the emission rates during the Harsh-MIRA drivecycle.

The real-world conversion efficiency of the catalytic converter is approximately $72-75$ per cent and is significantly lower than that measured during the legislative drive-cycle of $>90$ per cent. The realworld CO emission levels are approximately eight times higher than that of the legislative limits.

The emission performance of the vehicle for the Harsh-MIRA drive-cycle showed that emission monitoring using remote sensing would be inconclusive if the vehicles are allowed to operate within the highemission zone of the engine performance map. The experimental data show that the threshold margin for designating vehicles as gross polluting vehicles has been reached already by this new Euro-IV experimental vehicle for real-world driving. Hence, 
controlling the vehicle using remote sensing and telematics will not be beneficial if the vehicles operate outside the clean zone of the engine map.

\section{ACKNOWLEDGEMENT}

The authors would like to thank the AVERT project team (funded by the EPSRC and DTI LINK through the Foresight Vehicle Programme) for their support and funding for this work.

\section{REFERENCES}

1 Cornelius, S. J. Modeling and control of automotive catalysts. PhD thesis, Sydney Sussex College, Cambridge University, UK, 2001.

2 Eastwood, P. Critical Topics in Exhaust Gas Aftertreatment, 2000, pp. 7-32 (Research Studies Press Ltd).

3 Koltsakis, G. C. and Stamatelos, A. M. Modeling dynamic phenomena in 3-way catalytic converters. Chem. Engng Sci., 1999, 54, 4567-4578.

4 Pontikakis, G. and Stamatelos, S. Mathematical modeling of catalytic exhaust systems for EURO-3 and EURO-4 emission standards. Proc. Instn Mech. Engrs, Part D: J. Automobile Engng, 2001, 215.

5 Pontikakis, G. N. Modeling, reaction schemes and kinetic parameter estimation in automotive catalytic converters and diesel filters. PhD thesis, University of Thesaly, Greece, 2003.

6 Lund, C. D., Surko, C. M., Maple, M. B., and Yamamoto, S. Y. Effects of local reactant concentration perturbations in oscillatory catalysis. J. Chem. Physics, 1998, 108(13), 5565-5570.

7 Yamamoto, S. Y., Surko, C. M., Maple, M. B., and Pina, R. K. Spatio-temporal dynamics of oscillatory heterogeneous catalysis: $\mathrm{CO}$ oxidation on platinum, J. Chem. Physics, 1995, 102(21).

8 AVERT, Experimental data from AVERT project, 2001 (Motor Industries Research Association, UK).

9 Department of Trade and Industry Foresight Vehicle initiative,

http://www.foresightvehicle.org.uk/projects/ theme02.asp, 2001, accessed March 2004.

10 Samuel, S. Transient vehicle emission levels and fuel economy in real-world driving conditions. $\mathrm{PhD}$ thesis, Oxford Brookes University, UK, 2004.

11 Spindt, R. S. Air-fuel ratios from exhaust gas analysis. SAE paper 650507, 1965.

12 Stedman, D. H., Bishop, G. A., and Beaton, S. P. On-road remote sensing of $\mathrm{CO}$ and $\mathrm{HC}$ emissions in California. California Air Research Board, Contract A032-093, February 1994.

13 Stedman, D. H., Bishop, G. A., Peterson, J. E., Guenther, P. L., McVey, I. F., and Beaton, S. P.
On-road carbon monoxide and hydrocarbon remote sensing in the Chicago area. Illinois Department of Energy and Natural resources, Project ILENR/ RE-AQ-91/14, 1991.

14 United States General Accounting Office, Air pollution: unresolved issues may hamper success of EPA's proposed emissions program, GAO/RECD92-288, September 1992.

15 Jimenez, J. L., Koplow, M. D., Nelson, D. D., Zahniser, M. S., and Schmidt, S. E. Characterization of on-road vehicle NO emissions by a TILDAS remote sensor. Air and Waste Management Association, April 1999, 49, 463-470.

16 Summary of test results from Wisconsin EPA OBD project. Sierra research report SR98-10-02, 16 October 1998 (Sierra Research).

$17 \mathrm{http}: / /$ www.unece.org/trans/doc/2002/wp29grpe/ TRANS-WP29-GRPE-44-inf06e.pdf, Current and Future European Community Emission Requirements, June 2002 (European Commission).

18 United States Environmental Protection Agency, Federal Register - Document 40CFR, Part 86, 22 December 1998, Vol. 63, No. 245, pp. 70681-70697.

19 Austin, T. C., Ashby, H. A., and Carlson, T. R. An evaluation of loaded mode I/M testing at service stations. Sierra research report number SR88-12-02, 1988.

20 Baum, M. M., Kiyomiya, E. S., Kumar, S., and Lappas, A. M. Multi-component remote sensing of vehicle exhaust by dispersive absorption spectroscopy. 1 Effect of fuel type and catalyst performance. Environmental Sci. Technol., July 1998, 34.

21 Crookell, A. Consultation paper on requirements for remote sensing devices for gaseous emission monitoring - a European perspective. Funded by the European Commission's Competitive and Sustainable Growth Programme, REVEAL-1999-RD-0657, 13 July 2000.

22 Crookell, A. and Sinclair, P. Remote analysis of motor vehicle exhaust: the elusive emission factor. In Proceedings of the 3rd International Conference on Urban Air Quality, Measurement, Modeling, and Management, 19-23 March 2001, Loutraki, Greece.

\section{APPENDIX}

\section{Notation}

CO carbon monoxide

$\mathrm{NO}_{x} \quad$ oxides of nitrogen

OBD on-board diagnostics

ppm parts per million

THC total hydrocarbon

TWC three-way catalyst

$\lambda \quad$ relative air-fuel ratio 